\title{
Effect of an anti-oestrogen on implantation of mouse blastocysts
}

\author{
Jayasree Sengupta, S. K. Roy and S. K. Manchanda \\ Department of Physiology, All India Institute of Medical Sciences, New Delhi 110029, India
}

\begin{abstract}
Summary. Mouse blastocysts collected on Day 4 were cultured for $4 \mathrm{~h}$ in Whitten's medium containing $5 \mu \mathrm{g}$ CI-628 citrate, a specific oestrogen antagonist, and transferred to the uteri of pseudopregnant hosts. There was a significant reduction in the number of implantations observed on Day 11 when compared with those from blastocysts which were similarly transferred after culture in medium alone or in medium containing $1 \mu \mathrm{g}$ oestradiol-17 $\beta$ and $5 \mu \mathrm{g}$ CI-628 citrate. We suggest that this is further evidence for the involvement of embryonic oestrogen in implantation.
\end{abstract}

\section{Introduction}

Implantation involves an initial attachment of the blastocyst to the surface of luminal epithelium and this cellular contact could then allow an exchange of information from the blastocyst to epithelial cells. Although the nature of such a signal is still unknown, it is thought to be a humoral substance released by an implanting blastocyst (Heald, 1976). It has been proposed that steroids synthesized or accumulated in the blastocyst may play an important role in implantation (Dickmann, Dey \& Sengupta, 1976; George \& Wilson, 1978) and in triggering the local cellular events that occur at the site of implantation (Sengupta, Roy \& Manchanda, 1979). The present study was designed to test whether embryonic oestrogen is essential for implantation in the mouse by exposing blastocysts directly to an anti-oestrogen.

\section{Materials and Methods}

Random-bred Swiss mice were killed on Day 4 of gestation (Day 1 = day of finding copulatory plug) to recover blastocysts. After a brief wash in culture medium, the embryos were randomly assigned to one of three groups. In Group I the blastocysts were placed in glass tubes and cultured for $4 \mathrm{~h}$ in Whitten's culture medium supplemented with $0.3 \%$ crystalline bovine serum albumin (Sigma Co.) according to the method described by Whitten (1971). In Group II, blastocysts were similarly cultured for $4 \mathrm{~h}$ in medium containing $5 \mu \mathrm{g} \mathrm{Cl}-628$ citrate (Parke Davis Co., U.S.A.). In Group III, the culture medium contained $5 \mu \mathrm{g}$ CI-628 citrate and $1 \mu \mathrm{g}$ oestradiol-17 $\beta$; blastocysts were cultured for $4 \mathrm{~h}$. At the end of culture, the blastocysts from all 3 groups were rapidly examined under a stereomicroscope, washed in fresh culture medium under sterile conditions and then carefully transferred to the uteri of females on Day 3 of pseudopregnancy. An average of 7 or 8 blastocysts were transferred to each uterine horn. Pseudopregnancy in the host mice was induced by removing both oviducts on Day 1 of pregnancy. The host animals were killed on Day 11 and the number of implantations as well as fetal and placental weights were carefully recorded. A fetus was considered to be live and viable if it showed a fast-beating heart. A group of 7 normal pregnant mice (Group IV) was left 
untreated as control and these were also killed on Day 11 to assess the range of normal fetal and placental weights.

\section{Results}

As shown in Table 1, the percentages of live fetuses in Groups I and III were similar, but the treatment in Group II resulted in very few fetuses. Fetuses in all 3 groups were viable as observed from their heart beats. Placental weights differed little in the 4 groups; the fetuses in Group II were significantly heavier.

Table 1. Effect of exposure of Day-4 mouse blastocysts to an anti-oestrogen before transfer to the uteri of pseudopregnant hosts

\begin{tabular}{cccccc}
\hline Group & $\begin{array}{c}\text { No. of blastocysts } \\
\text { transferred (no. of } \\
\text { recipient uterine horns) }\end{array}$ & $\begin{array}{c}\text { Total no. of } \\
\text { viable fetuses } \\
(\%)\end{array}$ & $\begin{array}{c}\text { \% of females } \\
\text { with viable } \\
\text { fetuses }\end{array}$ & $\begin{array}{c}\text { Fetal wt } \\
\text { (mg) }\end{array}$ & $\begin{array}{c}\text { Placental wt } \\
\text { (mg) }\end{array}$ \\
\hline I & $130(17)$ & $52(40)^{*}$ & 58.8 & $14.25 \pm 0.08 \pm$ & $28.31 \pm 1.05$ \\
II & $128(17)$ & $21(16.4)^{* \dagger}$ & 35.3 & $28.94 \pm 2.67 \pm$ & $29.74 \pm 5.61$ \\
III & $114(15)$ & $42(36.8)^{\dagger}$ & 73.3 & $12.55 \pm 0.58$ & $27.47 \pm 1.29$ \\
IV & - & - & - & $13.26 \pm 0.74$ & $27.91 \pm 1.95$ \\
\hline
\end{tabular}

Values are mean \pm s.e.m.

*† Significantly different, $P<0.001$ (proportion, Z. test).

‡ Significantly different, $P<0.001$ ( $t$ test).

\section{Discussion}

The hormonal requirements for implantation have been known for a long time but the precise mechanisms which trigger embryo attachment and implantation remain to be understood. Blastocysts obtained from a number of species have been shown to contain two key steroidogenic enzymes and also steroids such as progesterone, oestradiol-17 $\beta$ and their metabolites (Fuchs \& Beling, 1974; Dickmann et al., 1976; George \& Wilson, 1978). In ovariectomized and progesterone-treated rabbits implantation is dependent upon embryonic oestrogen (Bhatt \& Bullock, 1974; Dey, Dickmann \& Sengupta, 1976; George \& Wilson, 1978), but this mechanism may not be applicable to mice and other rodents.

McCormack \& Greenwald (1974) and Sengupta et al. (1979) have shown that in mice ovariectomized at 15:00 h on Day 4, normal implantations occur. However, when such ovariectomized animals are injected intraperitoneally with an oestrogen antagonist such as CI-628 citrate, implantation failure was shown by the absence of characteristic blue dye sites and local cellular lysosomal enzymic changes in uterine epithelial cells surrounding the blastocyst (Sengupta et al., 1979). We therefore suggested that in addition to the systemic oestrogen source which supplies the steroid throughout the uterine horn, there may be a further need for local oestrogen to initiate the vascular response and other cellular events during the early stages of embryo attachment. In the experiments of Sengupta et al. (1979) the drug was given by intraperitoneal injection and so the present experiment was designed to expose the blastocysts directly. The finding that exposure of blastocysts to the anti-oestrogen significantly inhibited implantation is compatible with the hypothesis that blastocyst oestrogen could participate in inducing local cellular and vascular changes at implantation. Logeat, Sartor, Hai \& Milgrom (1980) have shown a local effect of the blastocysts on oestrogen and progesterone receptors in the rat endometrium. Nuclear receptors for both steroids were found in 2 -fold higher concentration in implantation sites than in non-implantation of regions of the endometrium of 
6-day pregnant rats. Moreover, this difference in receptor concentration was not observed in deciduomal tissue obtained from pseudopregnant animals. In mice and rats, implantation sites are associated with low uptake of exogenously administered $\left[{ }^{3} \mathrm{H}\right]$ oestradiol $-17 \beta$ in comparison with non-implantation uterine areas, suggestive of local saturation of oestrogen receptor sites with the steroid released from the blastocyst (Sartor, 1977; Ward, Frost \& Orsini, 1978). All these observations suggest that there is involvement of oestrogen at the site of implantation. On the other hand, rabbit blastocysts have the capacity to accumulate oestrogen and progesterone from the surrounding uterine fluid (Borland, Erickson \& Ducibella, 1977; Angle \& Mead, 1979) and also metabolize progesterone and androgens (Huff \& Eik-Nes, 1966; Singh \& Booth, 1978). Whether of embryonic origin or from a maternal source, oestrogen is likely to be present in blastocysts at the time of implantation.

Callantine et al. (1966) considered that CI-628 exerts its inhibitory effects on implantation in the rat by virtue of its anti-oestrogenic properties and not because of an anti-metabolic action. In the present study we found that fetuses obtained from blastocysts exposed to CI-628 were significantly heavier than those in the other groups while the placental weights remained unaffected. Fetal weight is known to be increased when the litter size is decreased (McKeown, Marshall \& Record, 1976) and there were fewer fetuses after exposure to CI-628, perhaps permitting better access of nutrients (Healy, McLaren \& Michie, 1960). However, Callantine et al. (1966) found no effect on fetal growth and development in rats treated with CI-628 for 13 days. Mouse blastocysts exposed to CI-628 for $24 \mathrm{~h}$ exhibited normal development when assessed in terms of their expansion in vitro (Sengupta, Dey \& Dickmann, 1977), and in the present study exposure to CI-628 and oestradiol-17 $\beta$ had no effect on subsequent proportions of viable fetuses. The evidence therefore indicates that CI-628 is not embryotoxic and its inhibitory effects on implantation are probably mediated through an anti-oestrogenic mechanism, supporting our view that oestrogen released from the blastocyst is essential for implantation. Oestrogen could enhance a local epithelial oestradiol- $17 \beta$ receptor translocation to the nucleus (Logeat et al., 1980) and such binding could lead to the release of secondary messenger molecules such as histamine and prostaglandins which have been shown to be involved in implantation in rodents (Kennedy, 1977; Dey, Johnson \& Santos, 1979; Johnson \& Dey, 1980).

This investigation was supported by funds from the Indian Council of Medical Research and the Family Planning Foundation of India. We thank the Parke Davis Company, U.S.A., for their generous gift of CI-628 citrate.

\section{References}

Angle, M.J. \& Mead, R.A. (1979) The source of progesterone in preimplantation rabbit blastocysts. Steroids 33, 625-637.

Bhatt, B.M. \& Bullock, D.W. (1974) Binding of oestradiol to rabbit blastocysts and its possible role in implantation. J. Reprod. Fert. 39, 65-70.

Borland, R.M., Erickson, G.F. \& Ducibella, T. (1977) Accumulation of steroids in rabbit preimplantation blastocysts. J. Reprod. Fert. 49, 219-224.

Callantine, M.R., Humphrey, R.R., Lee, S.L., Windsor, B.L., Schottin, N.H. \& O'Brien, O.P. (1966) Action of estrogen antagonist on reproductive mechanisms in the rat. Endocrinology 79, 153-167.

Dey, S.K., Dickmann, Z. \& Sengupta, J. (1976) Evidence that the maintenance of early pregnancy in the rabbit requires blastocyst oestrogen. Steroids $\mathbf{2 8}$, $481-485$.

Dey, S.K., Johnson, D.C. \& Santos, J.G. (1979) Is histamine production by the blastocyst required for implantation in the rabbit? Biol. Reprod. 21, 11691173.

Dickmann, Z., Dey, S.K. \& Sengupta, J. (1976) A new concept: control of early pregnancy by steroid hormones originating in the preimplantation $\mathrm{em}$ bryos. Vitams Horm. 34, 215-242.

Fuchs, A.R. \& Beling, C. (1974) Evidence for early ovarian recognition of blastocyst in rabbit. Endocrinology 95, 1054-1058.

George, F.W. \& Wilson, J.D. (1978) Oestrogen formation in the early rabbit embryo. Science, N.Y. 199, 200.

Heald, P.J. (1976) Biochemical aspects of implantation. J. Reprod. Fert., Suppl. 25, 29-52.

Healy, M.J.R., McLaren, A. \& Michie, D. (1960) Foetal growth in the mouse. Proc. $R$. Soc. $B$ 153, 367-379.

Huff, R.L. \& Eik-Nes, K.B. (1966) Metabolism in vitro of acetate and certain steroids by six-day old rabbit blastocysts. J. Reprod. Fert. 11, 57-63.

Downloaded from Bioscientifica.com at 04/26/2023 10:54:50AM 
Johnson, D.C. \& Dey, S.K. (1980) Role of histamine in implantation: dexamethasone inhibits estradiolinduced implantation in the rat. Biol. Reprod. 22, 1136-1141.

Kennedy, T.G. (1977) Evidence for a role for prostaglandins in the initiation of blastocyst implantation in the rat. Biol. Reprod. 16, 286-291.

Logeat, F., Sartor, P., Hai, M.T.V. \& Milgrom, E. (1980) Local effect of the blastocyst on oestrogen and progesterone receptors in the rat endometrium. Science, N.Y. 207, 1083-1085.

McCormack, J.T. \& Greenwald, G.S. (1974) Evidence for a preimplantation rise in oestradiol-17 $\beta$ levels on Day 4 of pregnancy in the mouse. J. Reprod. Fert. 41, 297-301.

McKeown, T., Marshall, T. \& Record, R.G. (1976) Infiuences on fetal growth. J. Reprod. Fert. 47, 167-181.

Sartor, P. (1977) Exogenous hormone uptake and retention in the rat uterus at the time of ovoimplantation. Acta endocr., Copenh. 84, 804-812.
Sengupta, J., Dey, S.K. \& Dickmann, Z. (1977) Evidence that embryonic oestrogen is a factor which controls the development of the mouse preimplantation embryo. Steroids 29, 363-369.

Sengupta, J., Roy, S.K. \& Manchanda, S.K. (1979) Hormonal control of implantation: a possible role of lysosomal function in the embryo uterus interaction. J. Steroid Biochem. 11, 729-744.

Singh, M.M. \& Booth, W.D. (1978) Studies on the metabolism of neutral steroids by preimplantation rabbit blastocysts in vitro and the origin of blastocyst oestrogen. J. Reprod. Fert. 53, 297-304.

Ward, W.E., Frost, A.G. \& Orsini, M.W. (1978) Oestrogen binding by embryonic and interembryonic segments of the rat uterus prior to implantation. Biol. Reprod. 18, 598-600.

Whitten, W.K. (1971) Nutrient requirements for the culture of preimplantation embryo in vitro. $A d v$. Biosci. 6, 129-141.

\section{Received 9 September 1980}

